\title{
Integrating prey dynamics, diet, and biophysical factors across an estuary seascape for four fish species
}

\author{
Michael Arbeider ${ }^{1, *}$, Ciara Sharpe ${ }^{1}$, Charmaine Carr-Harris ${ }^{2,3}$, Jonathan W. Moore ${ }^{1}$ \\ ${ }^{1}$ Earth to Oceans Research Group, Simon Fraser University, 8888 University Drive, Burnaby, British Columbia V5A 1S6, Canada \\ ${ }^{2}$ Skeena Fisheries Commission, 3135 Barnes Crescent, Kispiox, British Columbia, V0J 1Y4, Canada \\ ${ }^{3}$ Present address: Fisheries and Oceans Canada, 417 2nd Ave W, Prince Rupert, British Columbia, V8J 1G8, Canada
}

\begin{abstract}
Estuary food webs support many fishes whose habitat preferences and population dynamics may be controlled by prey abundance and distribution. Yet the identity and dynamics of important estuarine prey of many species are either unknown or highly variable between regions. As anthropogenic development in estuaries increases, so does the need to understand how these environments may be supporting economically, culturally, and ecologically important fishes. Here, we examine how important estuary fishes integrate their prey across the seascape and what may influence prey dynamics. Specifically, we surveyed juvenile coho salmon Oncorhynchus kisutch, juvenile sockeye salmon O. nerka, Pacific herring Clupea pallasii, and surf smelt Нypomesus pretiosus diets along with zooplankton abundance in the estuary of the Skeena River (British Columbia, Canada) at a relatively fine scale. We found diets were highly variable, even within a species, but 1 or 2 prey composed most diet contents per species. Juvenile coho salmon primarily consumed terrestrial insects and larval fish, whereas sockeye salmon primarily consumed harpacticoid copepods. In contrast, small pelagic fish (Pacific herring and surf smelt) primarily consumed calanoid copepods, which were the most abundant prey in the environment. We found that certain prey groups were correlated with biophysical factors. For example, calanoid copepod abundance was positively correlated with salinity, whereas harpacticoid copepod abundance was highest over eelgrass sites. Identifying key prey species and how they distribute within the estuary seascape is an integral link in understanding the food-web foundation of fish habitat use in areas under pressure from anthropogenic development.
\end{abstract}

KEY WORDS: Juvenile salmon · Small pelagic fish $\cdot$ Estuary $\cdot$ Diet $\cdot$ Prey $\cdot$ Oncorhynchus $\cdot$ Clupea Hypomesus

\section{INTRODUCTION}

Marine prey are highly heterogenous across space and time (Barry \& Dayton 1991), creating both opportunities and challenges for mobile consumers. For example, infrequent pulses of prey due to seasonal dynamics and prey phenology can create temporary prey hotspots for predators (Croll et al. 2005, Yang et al. 2008). Further variation of prey abundance across space and time may be driven by major habitat tran-

*Corresponding author: marbeide@sfu.ca sitions, abiotic preferences of prey, environmental dynamics, and top-down effects of predators (Telesh \& Khlebovich 2010, Lannin \& Hovel 2011, David et al. 2016). Some of the difficulties faced by mobile consumers that result from the heterogeneity of prey across seascapes are the risks of starvation and predation (Letcher \& Rice 1997, Pitchford 2001). To cope with this spatio-temporal variation in prey, predators respond behaviourally by modifying their distributions (e.g. migration) and search patterns (e.g. Lévy

() The authors 2019. Open Access under Creative Commons by Attribution Licence. Use, distribution and reproduction are unrestricted. Authors and original publication must be credited. 
walk) to increase encounter rates with prey patches (Croll et al. 2005, Sims et al. 2008). Alternatively, mobile predators may integrate across staggered, smaller pulses of prey that occur over the variable seascape (e.g. prey waves instead of hot spots) to achieve more extended and consistent feeding opportunities (Armstrong et al. 2016). Different species of predators have different prey preferences and foraging abilities and employ different search movements to survive and thrive in heterogeneous prey seascapes. Thus, understanding the prey dynamics of seascapes is a key component of understanding the ecology of their consumers (Boström et al. 2011).

Estuaries can be prey-rich places for planktivorous fishes (Selleslagh et al. 2012, Levings 2016), but they are driven by multiple biophysical processes that produce particularly dynamic prey fields. Here, we refer to estuaries as the tidally influenced portions of rivers that have saltwater influence and the constituent bays that have freshwater influence (Perillo 1995). Productivity in estuaries is derived from the combination of riverine inputs and upwelled ocean nutrients, as well as local production from sea grasses, salt marshes, benthic and epiphytic algae, and microbes (Cloern et al. 2014). Each of these sources have seasonal patterns, often creating large phytoplankton blooms followed by zooplankton blooms (Cloern 1996, Mackas et al. 2012). In addition, zooplankton within an estuary are challenged by complicated hydrodynamic effects of tides and currents that interface with a variety of habitats to remain in their optimal environment (Palmer 1988, David et al. 2016). For example, rising tides over intertidal areas can push pelagic zooplankton into high density patches (David et al. 2016). In contrast, benthic and epibenthic zooplankton are known to have higher site fidelity than pelagic species because they can bury or attach themselves to their substrate and avoid this redistribution (Palmer 1988). Temperature and turbidity are also strong drivers of zooplankton habitat preference and are linked with their growth and reproductive development (Morgan et al. 1997). In addition to natural variability, estuaries are also undergoing changes from anthropogenic activity that may impact the dynamics of natural factors (López Abbate et al. 2015). Thus, a dynamic mosaic of zooplankton prey provide the resource base for planktivorous fishes that may rely on estuaries for staging or important nursery habitats (Beck et al. 2001, Nagelkerken et al. 2015, Sheaves et al. 2015).

Multiple economically, culturally, and ecologically important small fishes such as juvenile coho salmon Oncorhynchus kisutch, juvenile sockeye salmon
O. nerka, adult Pacific herring Clupea pallasii, and adult surf smelt Hypomesus pretiosus are supported by zooplankton and other food sources in estuaries along the West Coast of North America (Table S1 in the Supplement at www.int-res.com/articles/suppl/ m613p151_supp.pdf). Food webs supporting juvenile coho salmon are well researched, though many studies are from systems in the California Current System like the Columbia River estuary or estuaries in Puget Sound (Table S1). These studies found large regional, seasonal, annual, and ontogenetic variability in juvenile coho salmon diets (Brodeur et al. 2007b, Daly et al. 2009, Bollens et al. 2010, Levings 2016). Juvenile coho salmon are considered generalists, eating decapod larvae, amphipods, pteropods, copepods, euphausiids, eggs, and various other larval crustaceans but are predominantly piscivorous and insectivorous (Brodeur 1991). Studies on sockeye salmon diets in estuaries reported that they consumed euphausiids, cirripeds, mysids, larval fish, and calanoid copepods as well as other crustaceans in minor amounts (Simenstad et al. 1982, Birtwell et al. 1987, Ajmani 2011). In contrast, Pacific herring and surf smelt can have variable diets but generally consume copepods and other crustaceans in coastal environments (Miller \& Brodeur 2007, Hill et al. 2015). To the best of our knowledge, few published reports on the estuarine diets of adult Pacific herring exist and none for adult surf smelt (Table S1). Overall, there is variable scientific understanding of the estuary diets of juvenile coho and sockeye salmon, Pacific herring, and surf smelt in Northeast Pacific estuaries. There are even fewer studies linking diets and prey distribution patterns (Bollens et al. 2010) to the understanding of the role of estuaries as staging and nursery habitats (Nagelkerken et al. 2015, Sheaves et al. 2015, McDevitt-Irwin et al. 2016).

This study focusses on fish diets and prey distributions in the Skeena River estuary, an important area for juvenile salmon and one that was also under consideration for anthropogenic development at the time of writing (CEAA 2016). The estuary region we focus on is within the larger Skeena River estuary, an area previously identified as having particularly high abundances of juvenile salmon during their migration: 2- to 8-fold greater abundance of juvenile salmon than other regions over several years of observation (Carr-Harris et al. 2015). The region supports juvenile salmon from throughout the Skeena watershed, with at least 40 different populations identified in the estuary (Carr-Harris et al. 2015, Moore et al. 2015) that enter at different times (Carr Harris et al. 2018), most likely forage there, and reside for vari- 
able amounts of time (Moore et al. 2016). The average estimated residencies for sockeye and coho salmon were 2 and $14 \mathrm{~d}$, respectively (Moore et al. 2016). Further work within this region identified different fish abundances associated with abiotic aspects of estuary habitat (Sharpe 2017); however, how the estuarine zooplankton community support salmon and other small pelagic fish in the Skeena River estuary remains unknown.

Here, we quantify the spatial and temporal dynamics of estuarine prey for 4 fish species and their relationships with biophysical aspects of their seascape. Specifically, we studied juvenile coho salmon, juvenile sockeye salmon, Pacific herring, and surf smelt in the estuary of the Skeena River in northern British Columbia, Canada. We asked (1) how are prey distributed in the estuary across space and time, (2) what are the most consumed and selected prey of these 4 fish species, (3) do biophysical factors of the estuary co-vary or predict diet variability, and (4) can variability in prey abundance be predicted by biophysical factors? We discovered that diets varied greatly across the small spatial and temporal scale of our study for each species, particularly salmon, and that a few prey taxa had consistently high abundances across the seascape while other prey were associated with different biophysical factors, such as salinity or the presence of eelgrass. These findings provide insight into important prey dynamics and identify biophysical factors through which potential change could impact food webs supporting key fish species-a recognized knowledge gap in on-going decision-making and planning processes in the Skeena River watershed (Pickard et al. 2015).

\section{MATERIALS AND METHODS}

We investigated the spatio-temporal dynamics of zooplankton prey along with the diets of 4 fish species in the estuary of the Skeena River. We mapped important prey abundance across our sampling sites and tested for trends in abundance between sites and sampling periods. Next, we ranked prey importance and selectivity with 2 common metrics and scored diet overlap across individuals within species to measure small-scale diet variability. Subsequently, we assessed whether variation in important prey abundance in diet samples and in the seascape could be predicted by biophysical factors through generalized linear regression.

\subsection{Study area}

The Skeena River is the second-largest watershed entirely in British Columbia, Canada, draining an area of $55000 \mathrm{~km}^{2}$. The Skeena River mixes with the ocean in Chatham Sound, a semi-enclosed basin of $\sim 1500 \mathrm{~km}^{2}$ (Ocean Ecology 2014), by travelling through 3 major passages. Our study area is situated at the end of the northern-most passage, Inverness, which directs $\sim 25 \%$ of the total flow of the Skeena River (Trites 1956). The study region (Fig. 1) is in the traditional territory of the Tsimshian First Nations and is a focus of a research program developed in collaboration with Lax Kw'alaams Fisheries and Skeena Fisheries Commission to improve understanding of estuarine use by juvenile salmon and the broader estuarine food web.

\subsection{Field sampling and laboratory methods}

For diet analysis, we lethally sampled (Simon Fraser University Animal Care 1107B-11; Fisheries and Oceans Canada licence XR 82 2016) 111 sockeye salmon Oncorhynchus nerka, 57 coho salmon O. kisutch, 57 Pacific herring Clupea pallasii, and 35 surf smelt Hypomesus pretiosus across 17 sampling occasions (from here on, referred to as 'sets'; Table 1). The 17 sets occurred across 9 sites, i.e. some sites had $>1$ sampling occasion while others only had 1. The 9 sites where samples were obtained were a subset of 25 sites from the ongoing research program (Fig. 1). Sites were chosen to represent 4 main habitat types available in the estuary-eelgrass, sandy bay, rocky shoreline, and open water (Sharpe 2017) - or were part of the long-term monitoring project (Carr-Harris et al. 2015). We collected fish with 2 sizes of purse seine; the larger net measured $73.2 \mathrm{~m}$ long by $9.1 \mathrm{~m}$ deep with $5.1 \mathrm{~cm}$ webbing at the tow end and $1.3 \mathrm{~cm}$ webbing at the bunt, and the smaller net measured $45.7 \mathrm{~m}$ long by $5.5 \mathrm{~m}$ deep with $1.3 \mathrm{~cm}$ webbing at the tow end and $0.64 \mathrm{~cm}$ webbing at the bunt end. The 2 sizes of net were used so we could target the entire water column of sites with varying depths without snagging the net on the estuary substrate. We enumerated each species of fish and calculated a catch per unit effort (CPUE) as a measurement of salmon abundance. Relative abundances from the smaller purse seine were standardized to the larger purse seine by multiplying the small net catches by the large net area (length by width) and net tow duration, then dividing by the area and tow duration of the small net. We aimed to 


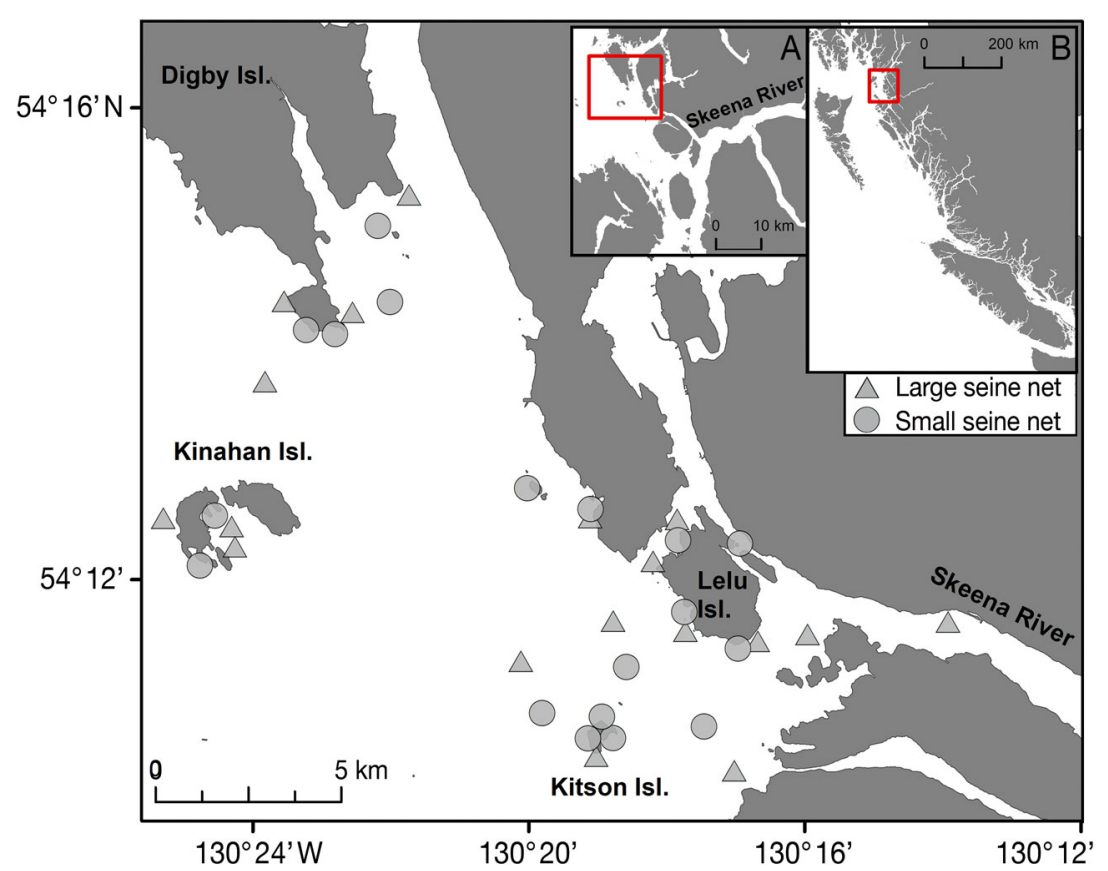

Fig. 1. Sampling locations according to net type used to capture fish across the Skeena River estuary. Note that vertical zooplankton tows were done concurrently at small seine net sampling events. Map inserts indicate location of sampling region in relation to (A) the mouth of the Skeena River, and (B) the coastline of British Columbia, Canada

Table 1. Number of non-empty diet samples for coho salmon, sockeye salmon, Pacific herring, and surf smelt across the sampling period and sites

\begin{tabular}{|llccccc|}
\hline $\begin{array}{c}\text { Day of } \\
\text { year }\end{array}$ & Site & $\begin{array}{c}\text { Set } \\
\text { no. }\end{array}$ & Coho & Sockeye & Herring & Smelt \\
\hline 131 & Porpoise Channel & 1 & 4 & 4 & 0 & 5 \\
134 & Lelu-rock & 2 & 0 & 10 & 10 & 5 \\
141 & Flora 1 & 3 & 2 & 2 & 0 & 0 \\
141 & Kitson & 4 & 0 & 10 & 10 & 0 \\
145 & Inverness Lelu & 5 & 9 & 0 & 3 & 0 \\
147 & Flora 1 & 6 & 5 & 6 & 0 & 0 \\
153 & Porpoise Channel & 7 & 5 & 10 & 0 & 0 \\
153 & Kinahans West & 8 & 0 & 10 & 0 & 0 \\
158 & Inverness Lelu & 9 & 5 & 5 & 5 & 5 \\
158 & Inverness NP & 10 & 5 & 11 & 3 & 5 \\
158 & Flora 2-eelgrass & 11 & 0 & 5 & 5 & 0 \\
159 & Kinahans-open water & 12 & 0 & 11 & 5 & 0 \\
160 & Flora 1 & 13 & 3 & 5 & 4 & 5 \\
161 & Kitson & 14 & 4 & 5 & 5 & 5 \\
161 & Kitson-open water & 15 & 0 & 5 & 0 & 0 \\
168 & Flora 1 & 16 & 5 & 6 & 0 & 0 \\
173 & Flora 1 & 17 & 5 & 11 & 5 & 5 \\
\hline
\end{tabular}

tow the seine hauls from the different sizes of net at similar speeds so that they would catch a similar diversity of fish. Fish samples were retained when there were at least 5 individuals of a species from any given set available for collection. We collected fish between 10 May and 21 June 2016 (see Table 1 for specific dates), to capture juvenile salmon around the peak of their outmigration, immediately storing lethal samples in seawater buffered $5 \%$ formalin solution.

Fish and diet samples were further processed in the laboratory. We measured fork length $(\mathrm{mm})$ and wet weight (g) (outside pat dried with paper towel) of all fish before excising their stomachs. Stomach contents were analyzed by identifying prey to the lowest possible taxonomic level. Abundance, total wet weight, and state of digestion was reported for each prey taxa in each stomach. Prey that was too digested to be identified was removed from the subsequent analysis. When diet contents could be identified to taxonomic group but were broken into parts, preventing an accurate count of individuals, we estimated abundance by using prey-specific linear regressions of known abundance on weight from our diet samples (Table S2 in the Supplement). One sockeye salmon, 4 coho salmon, and 1 Pacific herring had empty stomachs, leaving 110 sockeye salmon, 53 coho salmon, 56 Pacific herring, and 35 surf smelt diets in the analysis (Table 1).

We concurrently sampled for zooplankton in the environment at the 18 small-purse seine sites when fish were sampled (Fig. 1). Zooplankton were collected over 4 time periods: 13-20 May, 24 May to 1 Jun, 6-10 Jun, and 20-24 Jun (n $=71$, one sampling occasion was missed due to safety concerns from ocean conditions). We used a $250 \mu \mathrm{m}$ WP2 plankton net towed by hand vertically from a boat from $5 \mathrm{~m}$ below the surface to standardize the volume of water that was sampled. Samples were stored in a seawater buffered $5 \%$ formalin solution. We stained zooplankton with Rose Bengal to make them more visible, partitioned them with a Folsom plankton splitter, and sorted them until at least 400 individuals or the entire sample had been identified. We used a taxonomic level that was comparable to zooplankton identified within the diet samples and 
enumerated each group. We used abundance, corrected by the size of partition, as the final variable because all samples were from the same depth $(5 \mathrm{~m})$ and, therefore, volume of water $\left(3.9 \mathrm{~m}^{3}\right)$.

\subsection{Prey abundance across the seascape}

We identified 6 prey groups to investigate their spatial and temporal trends based on their common occurrence in diets of our study's focal fish in other studies. Harpacticoid and calanoid copepods, Cirripedia cyprids, decapod zoea, pteropods, and oikopleurans were chosen based on their prevalence in prior diet research that we compiled (Table S1) and representation in the zooplankton tows (i.e. we did not investigate prey groups such as larval fish that could avoid the plankton net nor terrestrially derived insects which would be concentrated at surface waters). We tested for differences in zooplankton abundance between sites and periods, for each taxa, using the non-parametric Kruskal-Wallis test by ranks. If there was a significant difference $(\alpha=0.05$ level) between groups, we used Dunn's test to determine which sites or periods were different. We determined the direction of any differences in abundance graphically.

\subsection{Importance, selectivity, and variability of prey in diets}

We used 2 indices that calculate consumption and selectivity of different prey by predators to determine which prey were most important and selected for by the study fish. First, we quantified prey consumption by the abundance, weight, and frequency at which it was consumed for every individual fish as a metric of prey importance to each fish species using a modified index of relative importance (IRI) (Bottom \& Jones 1990):

$$
\operatorname{IRI}_{i j}=\left(A_{i j}+B_{i j}\right) \times\left(F O_{j}\right)
$$

We calculated an IRI score for each prey taxa $(j)$ for each individual fish (i). A represents the percent abundance of prey $j$ in fish $i$. $B$ represents the percent wet weight biomass of prey $j$ in fish i. FO is the percent frequency of occurrence of prey $j$ across all individuals of a given species. The IRI metric considers prey 'importance' as best described by both its percent abundance and percent wet weight biomass within a diet because abundance and weight relationships are not equivalent across taxa (e.g. 1 fish larvae may account for a high percentage of prey biomass but a low percent of abundance, while many small copepods may do the opposite). Multiplying the cumulative percent of prey abundance and biomass by its percent frequency of occurrence scores rare prey lower than common prey and helps standardize IRI scores across varying individuals. Thus, individuals that did not consume a certain prey were removed from the IRI calculation after the FO was calculated so subsequent calculation of standard error and mean IRI for each prey per predator species do not include any zeros.

Second, we quantified prey electivity to investigate which food resources were appearing more often in the diets than expected by chance. Electivity indices are commonly used to provide inference on realized selectivity within a given prey seascape. We used Chesson's $\alpha$-electivity index (Chesson 1978) to rank the electivity of fish for each prey taxa $(j)$ :

$$
\alpha_{j}=\frac{d_{j}}{p_{j}} / \sum\left(\frac{d_{i}}{p_{i}}\right), \text { for } i=1, \ldots N,
$$

where $N$ is the number of prey taxa considered $(N=$ $7,9,11$, and 13 for coho salmon, sockeye salmon, herring, and smelt, respectively), $d_{j} / p_{j}$ is the relative frequency ratio of the proportion of prey $j$ in the $\operatorname{diet}(d)$ of an individual fish and in the plankton $(p)$ of its associated site, and $\Sigma\left(d_{i} / p_{i}\right)$ is the sum of this ratio for all prey taxa included in the analysis. The neutral electivity threshold, which suggests that a prey is being eaten in an equivalent proportion to what it would be encountered at by random in the environment, is defined for each predator as $1 / N$. We removed some species from analysis including prey that could readily avoid capture in the plankton net (e.g. larval fish, crab megalopa, cumaceans, isopods) or occurred in $<5 \%$ of tow samples (e.g. terrestrial insects) because they artificially inflated the electivity denominator $(p)$ due to systemic sampling error or general rarity (Brodeur et al. 2011). Prey that were not eliminated from this process but were still not present at some sites were assigned a $p$ that was 1 order of magnitude smaller than the smallest measured $p$ so that there were no zeros in the denominator. Since zooplankton samples were only taken at the 18 small purse seine sites during concurrent fish sampling (i.e. within $100 \mathrm{~m}$ of the seine at the same time), diet samples of fish caught from large purse seine sets were matched with the nearest plankton sample in time (average $\pm \mathrm{SD}: 2.7 \pm 2.3 \mathrm{~d}$ ) and space $(833 \pm 905 \mathrm{~m})$. If multiple plankton samples were taken within $250 \mathrm{~m}$ of the diet sample, we selected the sample closer in time. 
We quantified the amount of variability in diet samples across all individuals within a fish species by using Schoener's (1970) percent similarity index (PSI):

$$
\operatorname{PSI}_{x, y}=100\left[1-0.5\left(\sum_{j}^{n}\left|P_{X, j}-P_{Y, j}\right|\right)\right]
$$

where $P_{x, j}$ is the percent wet weight of prey $j$ in the stomach of individual $x, P_{y, j}$ is the percent wet weight of prey $j$ in the stomach of individual $y$, and $n$ is the total richness of prey consumed of the fish species concerned.

A PSI of 100 represents complete diet overlap, and zero represents complete dissimilarity. We removed rare prey, those with a FO $<5 \%$, before analysis. We determined our sample sizes were adequate to characterize diet composition because, once rare prey were removed, each species cumulative prey curve reached an asymptote.

We also quantified gut fullness across all individuals within each fish species. Gut fullness is also referred to as stomach fullness, an index of feeding intensity (Bottom \& Jones 1990), or feeding index (Price et al. 2013), and is commonly calculated as a percentage of body weight $(\% \mathrm{BW})$ :

$$
\% \mathrm{BW}=100 \times\left[M_{P} /\left(M_{T}-M_{P}\right)\right]
$$

where $M_{T}$ is the total wet weight of the fish prior stomach removal, and $M_{P}$ is the total wet weight of stomach contents.

\subsection{Predicting prey in diets and across the seascape}

We subsequently investigated patterns that could predict variability of important or selected prey across individuals. We chose prey (Table S3) with higher than average IRI and $\alpha$ scores per fish species and regressed their abundance across individual diets (including zeros) against a suite of covariates using generalized linear models with mixed effects (GLMM). The covariates included fish fork length, turbidity (Secchi disk depth), water temperature, distance from shore, total number of fish in set (in CPUE), and day of year. We formulated several hypotheses about the relationships between each of these variables, with explanations and examples for why they could be negative or positive (Table S4). We included a random effect for set in each model because individuals caught in the same net are considered non-independent.
We used a similar approach to the diet variability analysis to investigate relationships between variation in prey abundance with biophysical covariates of the estuary seascape. We used the same 6 prey from our prior prey analysis (Table 2): harpacticoid and calanoid copepods, Cirripedia cyprids, decapod zoea, pteropods, and oikopleurans. We used GLMMs to regress prey abundance counts from zooplankton tows against temperature, salinity, time of tow, main habitat type (eelgrass, sandy bay, rocky shore, or open water), and site distance from shore. We did not include turbidity because it had a Pearson correlation coefficient of 0.7 with salinity, which is known to be a strong determinant of zooplankton distributions. We explored hypotheses about the relationships between each of these variables, with explanations for why they could be negative or positive (Table S5). We included site as a random effect in all models to account for the expected covariation (non-independence) within sites that may be present across sampling time periods.

\subsection{Generalized linear model specifications}

GLMMs were used to provide information for our third and fourth questions (predicting prey in diets and the seascape). For both the diet variability and prey variability analysis, we fit single fixed-effect GLMMs with their respective random effect due to the limited amount of data and risk of overfitting (Babyak 2004, Hitchcock \& Sober 2004). We compared model fits of Poisson, negative binomial 1, and negative binomial 2, with log links using Akaike's information criterion corrected for small sample size (Burnham \& Anderson 2002) to determine which dis-

Table 2. Mean (SD) abundance and density (ind. $\mathrm{m}^{-3}$ ) per sample $\left(3.9 \mathrm{~m}^{3}\right.$ vertical plankton tow) of select prey species and their frequency of occurrence across samples $(n=71)$

\begin{tabular}{|lccc|}
\hline $\begin{array}{l}\text { Prey } \\
\text { species }\end{array}$ & Abundance & Density & Occurrence \\
\hline Calanoid & $1630(1563)$ & $418(401)$ & 1.00 \\
copepods & & & \\
Pteropoda & $92(109)$ & $24(28)$ & 1.00 \\
$\begin{array}{l}\text { Decapoda } \\
\text { zoea }\end{array}$ & $14(17)$ & $3(4)$ & 0.72 \\
$\begin{array}{l}\text { Oikopleura } \\
\text { Cirripedia }\end{array}$ & $333(582)$ & $85(149)$ & 0.92 \\
cyprids & $282(715)$ & $72(183)$ & 0.99 \\
$\begin{array}{c}\text { Harpacticoid } \\
\text { copepods }\end{array}$ & $45(109)$ & $12(28)$ & 0.76 \\
\hline
\end{tabular}


tribution family was appropriate for each responsepredictor variable combination. We fit models in $\mathrm{R}$ (R Core Team 2017) using the package glmmTMB (Brooks et al. 2017), which estimates parameters by maximizing likelihood. We tested the likelihood that covariates had a significant effect on improving model fit against an intercept-only model with a likelihood ratio test at the $\alpha=0.05$ level. However, because we did multiple comparisons using single covariate models for each response variable, we increased the probability of committing a Type I error (i.e. rejecting $H_{0}$ when $H_{0}$ is true) (Cabin \& Mitchell 2000). Thus, we applied a Bonferroni correction (Bonferroni 1936, Dunn 1961) to $\alpha$ of $\alpha / m$, where $m$ is the number of likelihood ratio tests per response variable. However, we discuss all results even if they were subsequently rejected by the Bonferroni correction because statistical power to detect effects in behavioural research can often be low (Jennions 2003, Nakagawa 2004). All covariates were centered and scaled (subtracted the mean from each observation and divided by 1 standard deviation) so that their effects could be comparable and to improve model convergence. If a covariate had a significant effect, we visually inspected their fit by examining the Pearson's and standardized residuals plotted against fitted values and checked for patterns. Subsequently, we graphically inspected the trends against real data for biological significance and confidence around the average prediction.

\section{RESULTS}

\subsection{Prey abundance across the seascape}

We found differences in abundance between prey groups, across sampling locations, and between time periods within several prey species. Calanoid copepods had the highest average abundance and were present in every sample (Table 2), making them the numerically dominant and most ubiquitous prey. Pteropods were the only other prey present in every sample but occurred at considerably lower average abundance than calanoid copepods. Cirripedia cyprids and oikopleurans had the next highest average abundances and frequencies of occurrence, followed by the more sporadically distributed harpacticoid copepods and decapod zoea. Three of the 6 species we tested for variability in abundance (calanoid copepods, pteropods, and decapod zoea) had statistically different medians at the $\alpha=0.05$ level between sites (Fig. 2). Differences between sites could suggest that they are not entirely independent and that some sites are possibly hotspots within the seascape for these species (Figs. $2 \& 3$ ). No single site appeared to
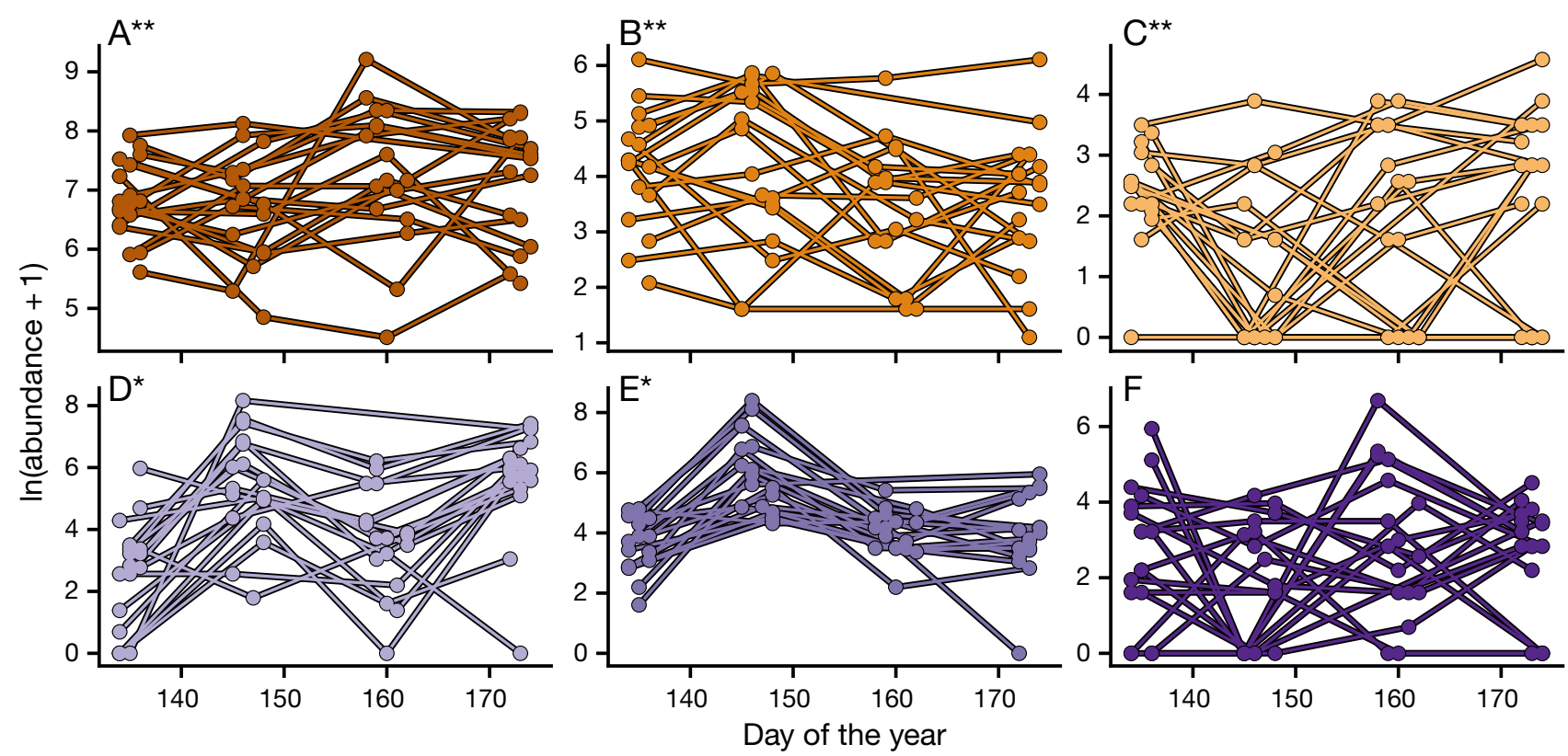

Fig. 2. Spatial and temporal patterns of abundance of (A) Calanoida, (B) Pteropoda, (C) Decapoda zoea, (D) Oikopleura, (E) Cirripedia cypris, and (F) Harpacticoida. Points connected by lines are samples from the same site within the Skeena estuary. Note that not all $y$-axes are equivalent and contain broken axes. Letters denoted by ${ }^{* *}$ and ${ }^{*}$ had significant site or sampling period differences, respectively, as detected by Kruskal Wallis tests with $\mathrm{p}<0.05$ 


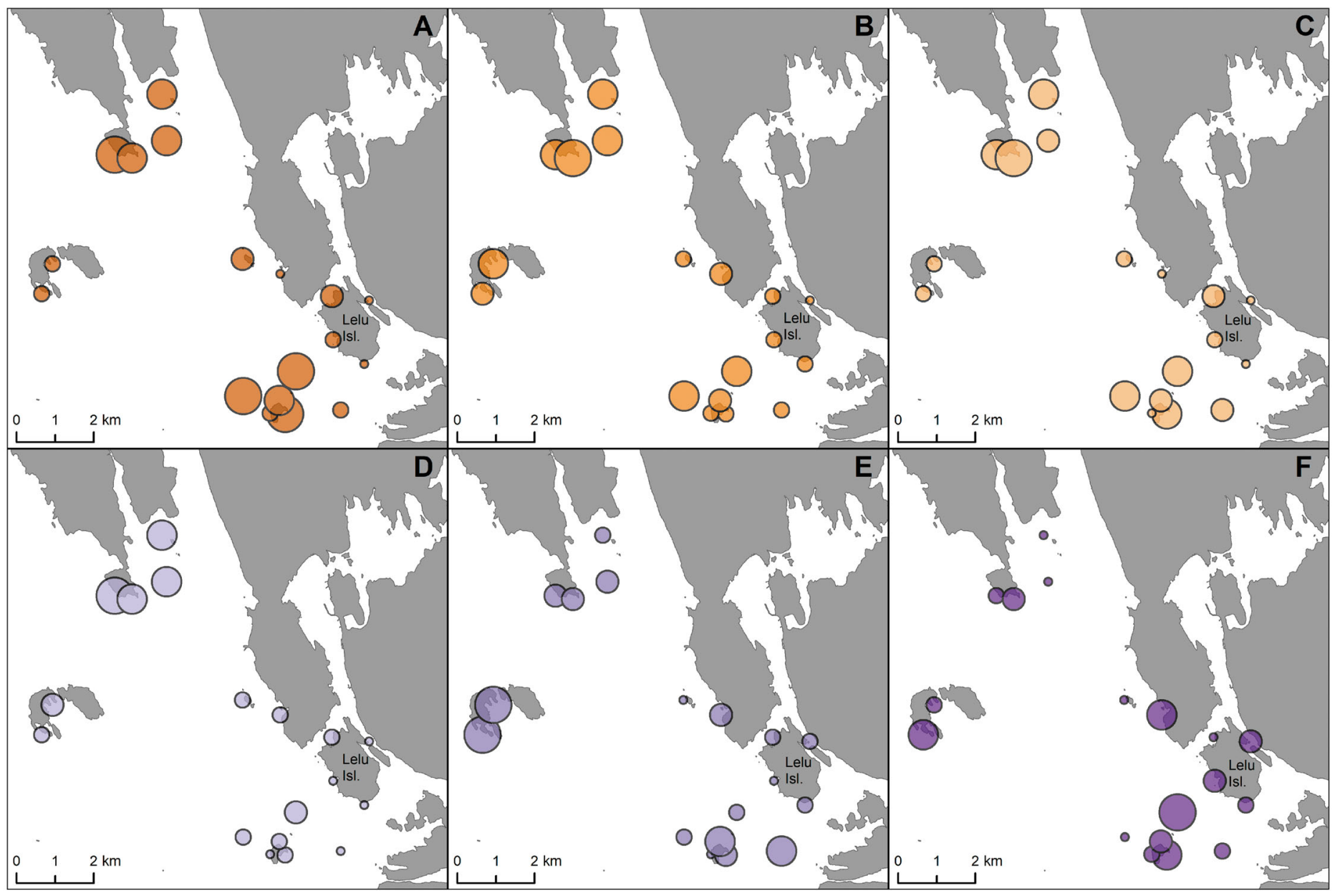

Fig. 3. Spatial distribution and relative mean abundance across all time periods of (A) Calanoida, (B) Pteropoda, (C) Decapoda zoea, (D) Oikopleura, (E) Cirripedia cypris, and (F) Harpacticoida across sampling sites in the Skeena River estuary. Bubble size is scaled by the relative abundance within a species, i.e. the size of bubbles is not comparable between species, only within. Large bubbles of species that had site level differences (A-C) could represent hotspots for those prey. White is water; grey is land

have consistently higher abundance of all species, but some sites had consistently below average abundance, which could represent an area with low prey availability for our focal predators. Two prey taxa, Cirripedia cyprids and oikopleurans, had statistically different medians between periods (Fig. 2). Only Period 2 (13-20 May) had a higher median than the other periods for Cirripedia cyprids, whereas Periods 2 and 4 (20-24 June) had higher medians than Periods 1 and 3 for oikopleurans (Fig. 2). Because only 2 of 6 prey showed differences between sampling periods and not in a consistent manner, we suggest that Period may not have as an important effect as Site, and thus we did not include Period as a random effect in subsequent models. Harpacticoid copepods did not have either temporal or site-specific differences in their abundance.

\subsection{Importance, selectivity, and variability of prey in diets}

We observed large variation in importance (IRI) and electivity $(\alpha)$ scores across individual fish within a species. There was considerable variability within the highest mean IRI scoring prey items for each fish species, with the values often ranging from $\sim 0$ to 1 order of magnitude larger than the mean. In the discussion, we refer to prey that have $>2$-fold the average IRI score as primary prey and those around the average as secondary prey.

For juvenile coho salmon Oncorhynchus kisutch, terrestrial-based insects and larval/juvenile fishes had the highest mean IRI scores, 2.4- and 2.1-fold higher than the third-highest prey, respectively (Fig. 4A). Insects were primarily Diptera (64\% by 


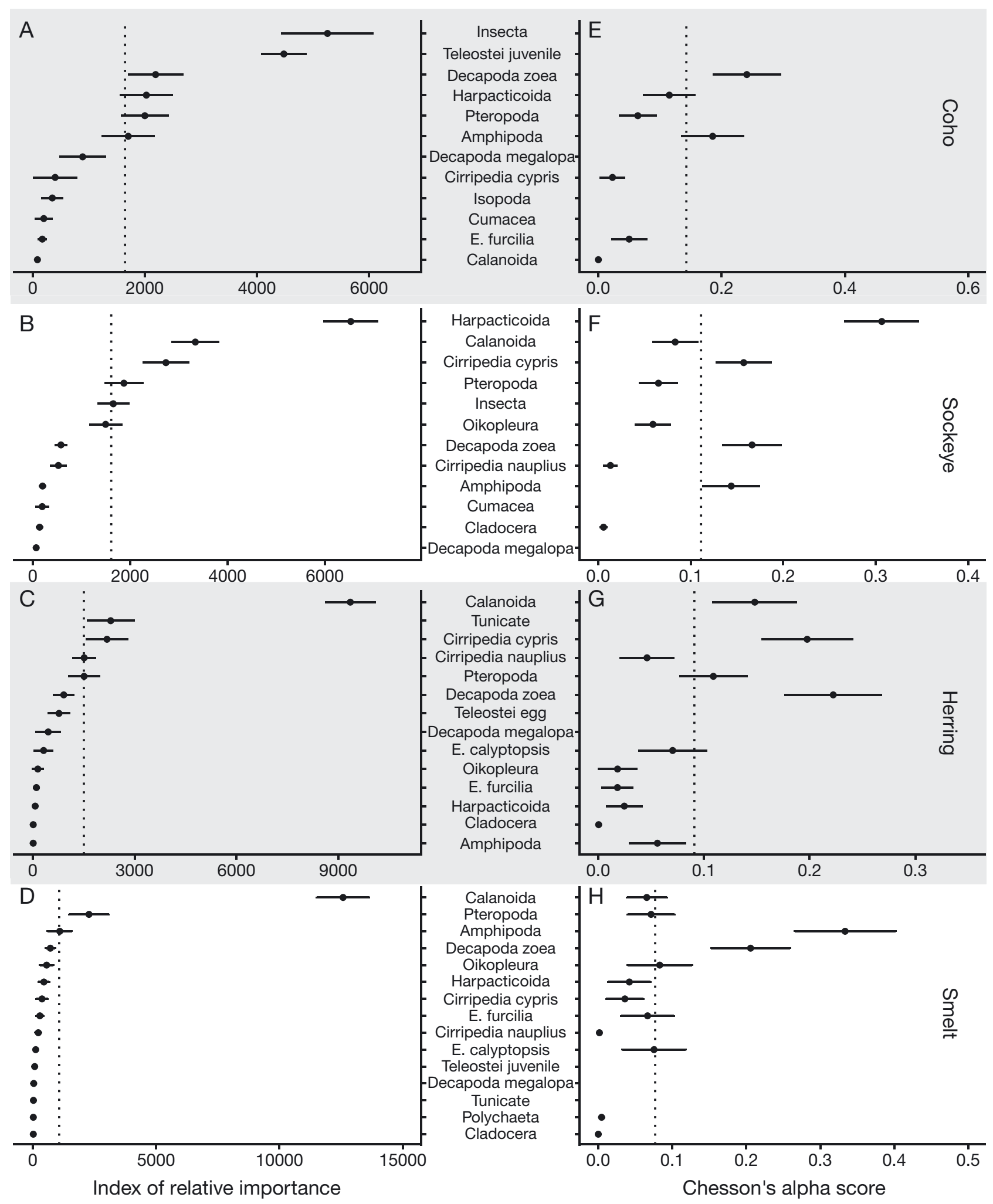

Fig. 4. Index of relative importance (IRI) and Chesson's electivity scores of each prey species with standard error for (A,E) coho salmon, $(B, F)$ sockeye salmon, $(C, G)$ Pacific herring, and $(D, H)$ surf smelt. Dotted lines represent the overall average IRI score for each fish species (A-D) and the neutral alpha selectivity threshold for each fish species (E-H). E.: Euphausiacea. Alpha scores above the neutral selectivity threshold suggest that a species is represented in the diet more than it is represented in the environment (i.e. proportionally higher in the diet), whereas values below the line suggest that the prey is proportionally higher in the environment. Note the reduced diversity of prey presented with Chesson's alpha because poorly sampled prey were removed. Only the prey that occurred in $>5 \%$ of diets are presented for both indices for coho salmon, sockeye salmon, and Pacific

herring, with a $10 \%$ occurrence cut-off for surf smelt because of the higher diversity of prey consumed in small amounts 
abundance), followed by Hemiptera (26\%), Coleoptera $(6 \%)$, and others (Collembola, Hymenoptera, Trichoptera, and Ephemeroptera). Only $23 \%$ of juvenile and larval fish were identified to family or lower, which were either Pleuronectidae $(86 \%)$ or Pacific herring Clupea pallasii (14\%). Decapod zoea (primarily from infraorder Brachyura), harpacticoid copepods, gastropods (Limacina pteropods when identifiable to genera), and amphipods also had higher than average mean IRI scores. Amphipods were primarily Gammaridea (83\%) with a notable $47 \%$ of Gammaridea being a high-intertidal family, Talitridae. The remaining amphipods (17\% by abundance) were Hyperiidae. Coho salmon had the highest electivity for decapod zoea followed by amphipods (Fig. 4E). The mean harpacticoid copepod electivity score was slightly below the neutral selectivity threshold. All other prey groups scored below the neutral selectivity threshold, i.e. were consumed at lower frequencies than their relative frequencies in the environment.

In juvenile sockeye salmon O. nerka, harpacticoid copepods had the highest mean IRI score, 2-fold higher than their next highest ranked prey (Fig. 4B). Calanoid copepods, Cirripedia cyprids, gastropods (Limacina pteropods when identifiable to genera), and terrestrial-based insects (majority Diptera and Hemiptera) also had higher than average mean IRI scores. It is interesting to note that 5 individuals also consumed adult stages of the salmonid parasite from the family Caligidae, which has also been observed in southern British Columbia (Price et al. 2013). Juvenile sockeye salmon had the highest electivity for harpacticoid copepods followed by decapod zoea, Cirripedia cyprids, and amphipods (Fig. 4F).

Calanoid copepods had the highest mean IRI scores for both adult Pacific herring and adult surf smelt Hypomesus pretiosus, 4- and 5.5-fold higher than their next highest ranked prey, respectively, for each fish species (Fig. 4C,D). Ascidian tunicates and Cirripedia cyprids were the only other Pacific herring prey whose mean IRI scores were higher than the overall mean IRI. Herring had the highest electivity for decapod zoea followed by Cirripedia cyprids, calanoid copepods, and gastropods with nearly neutrally electivity for euphausiid calyptopsis (Fig. 4G). Gastropods, all of which were unidentifiable beyond Gastropoda, were the only other surf smelt prey whose mean IRI score was above average. Smelt had the highest electivity for Hyperi- idea amphipods followed by decapod zoea and had neutral electivity for oikopleurans, ephausiid calyptopsis and furcilia, gastropods, and calanoid copepods (Fig. 4H). Although both herring and smelt had a high electivity value for decapod zoea, it was only found in 47 and $51 \%$ of individuals, respectively, and zoea were not consumed in large quantities. High electivity and generally low presence in the diet could mean that when zoea were encountered, despite their rarity, they were opportunistically targeted by both predators.

We found that diets and gut fullness within each species were highly variable with low diet overlap between individuals. The mean PSI values across all individuals within a species were all $<50$ on average except for surf smelt (Table 3), meaning that diets were frequently $>50 \%$ different across individuals of the same species. When we examined PSI pair-wise comparisons that were done between individuals from the same set (still of the same species), we found that the average PSI values increased, but 2 species still had PSI values below 50\%: coho salmon and Pacific herring. Average percent gut fullness was comparable to other studies on coho and sockeye salmon in estuary and nearshore environments if not slightly higher (Bottom \& Jones 1990, Healey 1991, Brodeur et al. 2007a, Price et al. 2013). In contrast, surf smelt and Pacific herring had less than half the gut fullness of both salmonids (Table 3 ).

\subsection{Predicting prey in diets and across the seascape}

We found 3 relationships between prey diet abundance and several biophysical factors that had parameter estimates that were statistically different than a null model by using likelihood ratio tests at the Bonferroni corrected $\alpha=0.05$ level, and 8 additional relationships when $\alpha$ was uncorrected (Fig. S1, Table S6 in the Supplement). The abundance of lar-

Table 3. Average percent similarity index (PSI) values with standard error for each fish species between all individuals and between only individuals from the same sets, mean gut fullness (\% body weight) with standard deviation, and fork length (FL) range

\begin{tabular}{|lcccc|}
\hline Fish species & $\begin{array}{c}\text { Mean } \\
\text { PSI (SE) }\end{array}$ & $\begin{array}{c}\text { Mean set } \\
\text { PSI (SE) }\end{array}$ & $\begin{array}{c}\text { Mean gut } \\
\text { fullness (SD) }\end{array}$ & $\begin{array}{c}\text { FL range } \\
\text { (mean) (mm) }\end{array}$ \\
\hline Coho salmon & $20.2(0.85)$ & $26.9(3.92)$ & $0.91(0.86)$ & $84-136(102)$ \\
Sockeye salmon & $23.7(0.36)$ & $50.6(4.70)$ & $0.83(1.11)$ & $59-109(82)$ \\
Pacific herring & $32.6(0.79)$ & $41.6(6.58)$ & $0.38(0.73)$ & $68-168(125)$ \\
Surf smelt & $52.3(1.30)$ & $57.1(7.53)$ & $0.34(0.34)$ & $106-168(134)$ \\
\hline
\end{tabular}


val fish in coho salmon diets decreased with increasing distances from shore (Fig. S1A). Insect abundance in coho salmon diets decreased with increasing temperature (Fig. S1B), possibly due to increased water volume (flow) from the river and increased delivery of upriver insects. Day of year was positively correlated with harpacticoid copepod abundance in sockeye salmon diets (Fig. S1G). The following 8 relationships were only significant at the uncorrected $\alpha=0.05$ level. Increased total set CPUE (total abundance) decreased the number of insects in coho salmon diets (Fig. S1C) and the number of calanoid copepods in Pacific herring diets (Fig. S1I), possibly because of exploitative competition. Insect and decapod zoea abundance in coho salmon diets increased with Secchi depth (Fig. S1D,E), possibly due to increased ability of fish to see insects stranded in surface waters and decapods within the water column in clearer water. Decapod zoea abundance in coho salmon diets also increased with coho salmon length (Fig. S1F), but this relationship appears to be driven by outlying data points. Water temperature was pos- itively correlated with harpacticoid abundance in sockeye salmon diets (Fig. S1H). However, day of year and temperature were highly correlated for sets with sockeye salmon samples (Pearson's correlation coefficient $=0.65$ ) and day of year fit better upon visual inspection. Calanoid copepod abundance in Pacific herring diets increased with distance away from shore (Fig. S1J), but the confidence intervals on this relationship are particularly large. Calanoid copepod abundance in surf smelt diets decreased with fish length (Fig. S1K), a possible indicator that larger individuals were targeting a different prey for consumption.

We found 3 relationships between prey abundance in the environment with biophysical factors that had parameter estimates statistically different than zero at the Bonferroni-corrected $\alpha=0.05$ level and 3 additional relationships when $\alpha$ was uncorrected (Fig. 5, Table S7); however, each relationship's biological significance is variable. The following 3 relationships were statistically significant after the Bonferroni correction. Calanoid copepod and oikopleuran abun-
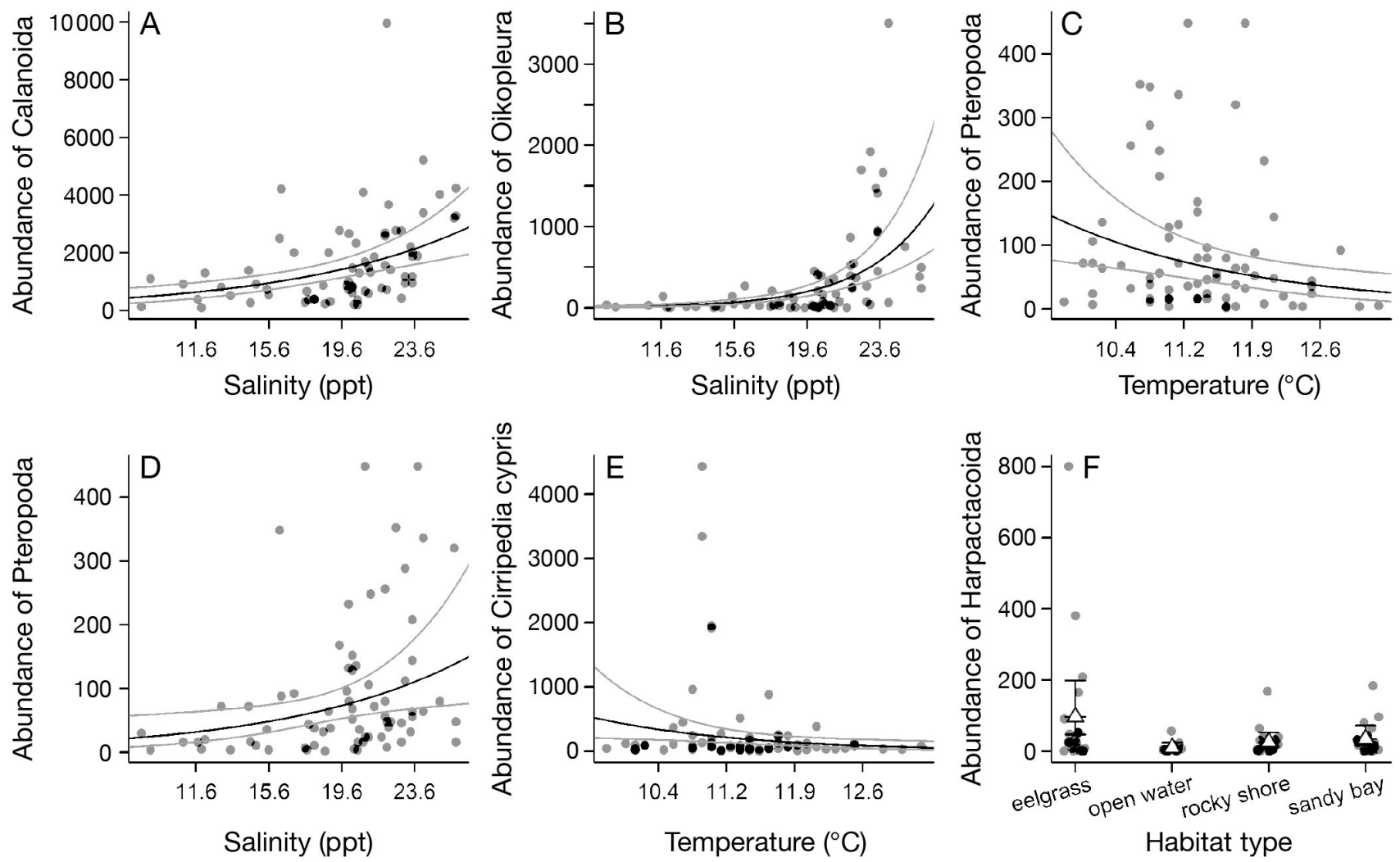

Fig. 5. Predicted relationships between the abundance of several important prey in the environment and biophysical aspects of the seascape within the Skeena estuary. Each light grey point is a site's measurement across sampling periods. The dark middle lines and the white triangles in (F) are the average model predictions. The outer gray lines and whiskers are the $95 \%$ confidence intervals calculated from the respective GLMMs. (A-C) are statistically significant at $\alpha<0.05$ after the Bonferroni correction. (D-F) are only statistically significant before the Bonferroni correction 
dance were positively correlated with salinity, possibly driven by these species' natural salinity tolerances. Both relationships with salinity appeared to have a significant biological effect (Fig. 5A,B). Pteropoda abundance was negatively correlated with temperature, but there was quite a bit of variability in abundance around the middle temperatures (Fig. 5C). The following 3 relationships were only statistically significant when $\alpha$ was uncorrected. Pteropoda abundance was positively correlated with salinity (Fig. 5D). Cirripedia cyprid abundance was negatively correlated with temperature (Fig. 5E). Harpacticoid copepods were more abundant on average at sites with eelgrass substrate compared to sites over open water or close to rocky shores and had a slight tendency to be more abundant than sites that were sandy bays (Fig. 5F). No biophysical factors predicting decapoda zoea abundance had statistical support.

\section{DISCUSSION}

Estuaries are particularly valued as key nursery habitats for a variety of fish species (Beck et al. 2001), where the dynamics of prey resources are an integral component of the nursery function (Sheaves et al. 2015). Here we found that 4 co-occurring estuary fish species relied on multiple prey that were dynamic across space and time. Our results also highlight high variability in diet contents within a small region and even between fish of the same species from the same seine set, whereas prior research often contrasts diets over seasons, years, or regions (Simenstad et al. 1982, Brodeur et al. 2007b, Hill et al. 2015). Biophysical factors predicted some of the variability in fish diets and prey in the environment. Thus, we provide rare empirical evidence for the spatio-temporal dynamics of prey and how predators integrate across them within a major estuary. The spatio-temporal prey mosaic has been previously suggested as a critical but understudied dimension of the role of estuaries as important refuges and nursery habitats (Nagelkerken et al. 2015, Sheaves et al. 2015).

\subsection{Prey distribution across space and time}

Our study fills recognized knowledge gaps for the Skeena River estuary (Pickard et al. 2015) by furthering our understanding about how prey are distributed during the period of highest juvenile salmon abundance (Carr-Harris et al. 2015, Sharpe 2017).
Prey abundance and distribution can determine their availability to predators (Griffiths 1973, 1975), so it is important to understand these features of the prey mosaic when considering how predators integrate with prey. Calanoid copepods showed consistent differences in abundance between sites, but because they were the most abundant and ubiquitous zooplankton prey, the sites with low abundance still had higher abundance than most other prey groups. Calanoid copepods' relatively high abundance has the potential to make them one of the most available prey (Griffiths 1975). Cirripedia cyprids and oikopleurans were present in moderate abundance and showed different temporal patterns across sites, with Cirripedia cyprids having a single temporal peak in abundance while oikopleurans had two. Peaks in abundance could be interpreted as differing bloom phenologies between these 2 groups and could affect their availability by matching or mismatching predators' estuary timing (Cushing 1990). Decapod zoea and harpacticoid copepods had the overall lowest average abundance and sporadic distributions, which could increase the search intervals (or decrease encounter rates) for this patchier prey (Sims et al. 2008). We did not effectively sample for larval fish or terrestrial insects (Brodeur et al. 2011), which are also known to be common prey (Table S1 in the Supplement). But overall, the prey field in the Skeena River estuary appears to be saturated by calanoid copepods with temporally variable abundances of Cirripedia cyprids and oikopleurans and low and patchy abundance of decapod zoea and harpacticoid copepods.

\subsection{Important and selected prey}

Our study also addresses a gap in knowledge for juvenile coho Oncorhynchus kisutch and sockeye salmon $O$. nerka diets in the Skeena River estuary (Pickard et al. 2015), as well as for the co-occurring and highly abundant small pelagic fishes in the area (Sharpe 2017): Pacific herring Clupea pallasii and surf smelt Hypomesus pretiosus. Despite the observed diet heterogeneity within sets, each species often consumed 1 or 2 prey most often and in high abundance or weight, here referred to as primary prey, followed by a few secondary prey that were consumed at a magnitude more than all remaining prey. Primary prey for coho salmon were insects and larval fish, which is consistent with prior research in British Columbia (Manzer 1969, Osgood 2016). Although we did not include insects and larval fish in 
the electivity analysis, their ubiquity in diets across other regions along the west coast of North America (Table S1) and relatively high energy density to other prey (Duffy et al. 2010) leads us to presume they were likely selected for. Coho salmon also selected for decapod zoea and gammarid amphipods in the estuary environment. Harpacticoid copepods were the most important and selected for prey by sockeye salmon, followed by decapod zoea, amphipods, and Cirripedia cyprids. We believe that this research is the first record of juvenile sockeye salmon primarily foraging on harpacticoid copepods in estuaries. Harpacticoid copepods were also an important secondary prey for coho salmon in our estuary and are a primary prey in other estuaries for coho as well as for chum O. keta, pink O. gorbusha, and ocean-type Chinook O. tshawytscha salmon (Healey 1979, 1980, Godin 1981, Simenstad et al. 1982, Macdonald et al. 1987, Northcote et al. 2007). By contrast, the primary prey for both Pacific herring and surf smelt were calanoid copepods. Whereas herring selected for calanoid copepods, Cirripedia cyprids, and decapod zoea, surf smelt only selected for amphipods and decapod zoea, with neutral affinity for calanoid copepods. All 4 species consumed pteropods as a secondary prey and selected for decapod zoea, and all but Pacific herring selected for amphipods, suggesting that these prey could be an energetically desirable or easily caught prey across predator taxa (Emlen 1966).

The drivers of the difference in the primary copepod prey between salmonid and small pelagic fish in this study can be examined in the context of ontogenetic niche theory (Werner \& Gilliam 1984) and by how prey activity can affect its availability to predators (Griffiths 1973). Small pelagic fish fed heavily on calanoid copepods, whereas juvenile salmonids relied more on harpacticoid copepods. Harpacticoid copepods are generally more sedentary than calanoid species because they are epibenthic and phytal, primarily feeding on epiphytic and macroalgae as well as detritus, bacteria, and fungi (Chandler \& Fleeger 1987, Steinarsdóttir et al. 2010), whereas calanoid copepods primarily feed actively in the water column (Mauchline 1998). In addition, harpacticoid copepods have slower burst speeds, relative to species of calanoid copepods who are known for their evasive behaviour (Leising \& Yen 1997, Buskey et al. 2002). Juvenile sockeye salmon are facultative planktivores, primarily targeting and consuming one prey item at a time (Lazzaro 1987), and are known to select for slower, larger prey in lakes when it is available (Eggers
1982). This is consistent with our observation that juvenile sockeye salmon selected for the slower harpacticoid copepods while consuming calanoid copepods less than their relative availability (with regards to abundance) in the environment. Even in coastal environments where harpacticoid copepods are often not found in the water column as an alternative prey, juvenile sockeye salmon eat calanoid copepods at proportions near or less than their availability in the environment (Price et al. 2013), possibly due to the difficulty to capture them. In contrast, Pacific herring consumed calanoid copepods selectively, and surf smelt consumed them with neutral selectivity (i.e. neither selected for nor avoided). Pacific herring and surf smelt may be better adapted to handle the quick, abundant, and pelagic calanoid copepods because they can create strong suction using their round mouths and buccal cavities, and even filter-feed at high prey densities (Gibson \& Ezzi 1985, Lazzaro 1987). The physiological adaptations of small pelagic fish are likely highly selected for because they spend much of their ontogeny at sizes relatively close to their full size, whereas juvenile salmon quickly grow to larger sizes and can use different foraging tactics on different types of prey (Werner \& Gilliam 1984, Daly et al. 2009, Duffy et al. 2010). This contrast in foraging patterns between juvenile salmon and small pelagic species illuminates key differences in how these fish species may integrate with the prey layer of estuarine seascapes.

Differences within the diets of small pelagic fish may suggest subtle behavioural differences that drive how they integrate with their prey in estuaries too. We found Pacific herring selected Cirripedia cyprids and barely consumed hyperiid amphipods, whereas surf smelt highly selected for hyperiid amphipods and consumed Cirripedia cyprids at relatively low quantities. Hyperiid amphipods and Cirripedia cyprids could be distinguishable to herring and smelt as they have considerably different morphologies, colour and refraction, and swimming patterns (Giske et al. 1994). The differences in foraging patterns between these 2 pelagic fish could be the result of differences in visual capabilities or light attenuation of prey that makes one more discernable than the other (Giske et al. 1994), or the distribution of predators and prey in the water column is such that they overlap/encounter the prey more frequently (Eggers 1977), or the differences could relate to differences in feeding morphology (Labropoulou \& Eleftheriou 1997) or some type of other learned preference (Brown \& Laland 2003). 


\subsection{Biophysical factors and diet variability}

Variability of prey abundance in diet samples for each predator was linked to some biophysical factors. We suggest that abiotic environmental factors could affect how predators integrate with their prey across the seascape in addition to inherent physiological constraints of the predators. We found that increasing Secchi depth, our index for water clarity, increased the abundance of 2 important prey in coho salmon diet samples: decapod zoea and terrestrial insects. Less turbid conditions may increase capture success of live decapod zoea (Berg \& Northcote 1985, Gregory \& Northcote 1993) or increase the line of sight to surface waters where expired or non-evasive terrestrial insects concentrate (Tschaplinski 1987). Insect prey in coho salmon diets also increased with colder water temperatures. As river temperatures were cooler than ocean temperatures during our sampling period, cool surface temperatures may correlate with increased riverine prey subsidies that are flushed down from upstream into certain areas (Tschaplinski 1987). Finally, calanoid copepod abundance decreased in Pacific herring diets as the set total CPUE of all fish increased. Since calanoid copepods were eaten by herring, smelt, and sockeye salmon in this study, this inverse relationship may suggest per capita calanoid copepod consumption rates decrease when the combined abundance of these multiple predators is high (Arditi \& Ginzburg 1989, Sih et al. 1998).

We found that biophysical characteristics did not explain variation of calanoid copepod abundance in surf smelt diets nor of Cirripedia cyprids in sockeye salmon and Pacific herring diets. The lack of statistical or biologically relevant relationships between these predator-prey pairs suggests that they are not affected by biophysical processes or that we did not identify the correct process. We also must acknowledge the possibilities that processes such as stochastic variation and insufficient sample size could affect our observed results. Furthermore, prey may have been consumed elsewhere and thus not directly related to the biophysical factors from the site. However, the effects from biophysical factors we detected, as well as others, influence how different predators integrate with their prey across the estuary seascape in time and space.

We found an additional seasonal pattern of harpacticoid copepod abundance in juvenile salmon diets that was not linked directly to any biophysical variables. The abundance of harpacticoid copepods in sockeye salmon diet samples increased with day of year. In theory, zooplankton production and abundance may increase over time in the spring and summer towards a seasonal maxima (Mackas et al. 2012); however, we did not find a relationship with harpacticoid abundance across time in our study. The lack of an increasing trend of harpacticoid abundance in the environment could be explained by topdown control of predators in areas with high production of prey (Rudstam et al. 1994, Yang et al. 2008). Harpacticoid copepod production may have been increasing, but their abundance did not because of high predation rates by juvenile sockeye salmon (Sibert 1979). Interestingly, the prevalence of harpacticoid copepods increased across time within coho salmon diet samples also (relationship not statistically significant), and harpacticoid copepods were consumed above average compared to other prey types. Thus, it may be possible for juvenile salmon to have collectively consumed harpacticoid copepods in the environment at a rate equivalent (or even greater) to their production as a form of top-down control (Healey 1979, Sibert 1979, Godin 1981, Fujiwara \& Highsmith 1997).

\subsection{Biophysical factors and plankton abundance}

Although we found no biophysical predictors of harpacticoid copepod abundance in diets, we did find that they were more abundant over eelgrass habitats than other habitats in the seascape. Site-specific hotspots of harpacticoid abundance were not discernable across time. Yet at sites where eelgrass was present, mean abundance in the water column was higher than at sites beside rocky shoreline or over open water. Eelgrass is known to support higher densities of harpacticoid copepods and is likely a population source (Hosack et al. 2006, Kennedy et al. 2018). Multiple studies have shown that juvenile salmon are capable of consuming large proportions of total harpacticoid production (Healey 1979, Godin 1981, Fujiwara \& Highsmith 1997). Therefore, degradation of eelgrass may affect prey productivity and could affect salmon foraging behaviour and potentially survival. In our system, sockeye and coho salmon abundances were consistently highest in the region of a particularly large eelgrass bed, Flora Bank (Carr-Harris et al. 2015, Sharpe 2017). We speculate that the Flora Bank eelgrass habitat may be an important source of harpacticoid copepods for these young salmon. Eelgrass habitat has previously been identified as a conservation priority because of its role as a productive food source for multiple juvenile 
fish species in other estuaries (McDevitt-Irwin et al. 2016). The Flora Bank region was the proposed location of major industrial developments (Moore et al. 2015, CEAA 2016), and previous assessment reports identified information on food web-habitat connections as 'high prioritization' data gaps (Pickard et al. 2015). Establishing these food-web habitat connections in areas poised for development is an important step in identifying the potential habitat value of estuarine seascapes to species of interest. The next steps are to identify species-specific predator-prey responses to possible impacts on habitats involved in supporting the estuary prey mosaic, such as eelgrass bed fragmentation or reductions in shoot density (Lannin \& Hovel 2011, Ljungberg et al. 2013, Chacin \& Stallings 2016).

The abundances of other zooplankton prey within the estuarine seascape were related to biophysical processes through space and time in multiple ways. Calanoid copepods, pteropods and decapod larvae showed site level consistencies in their abundance over time, which could indicate that certain locations are acting as prey hotspots. The best fit predictor of variability in calanoid copepod abundance was salinity, a common gradient in estuaries and driver of zooplankton distributions (Telesh \& Khlebovich 2010). Increasing salinity was correlated with increases in pteropods, a secondary prey for all of our predators, and oikopleurans, a prey that was marginally consumed by sockeye salmon in this study but is often found in the diets of other juvenile salmon (Manzer 1969, Landigham et al. 1998, Brodeur et al. 2007b). Although the salinity gradient and abundance patterns of calanoid copepods and pteropods were associated with sites, there was still variability within the salinity gradient at sites across time. Oikopleurans did not show any site-level persistence in abundance patterns despite being correlated with salinity. We suggest that this prey group is responding to dynamic environment forcing rather than being statically abundant in a specific location. Learning how prey are influenced by biophysical processes, like salinity (Telesh \& Khlebovich 2010), or habitat features like eelgrass patches (Lannin \& Hovel 2011, Ljungberg et al. 2013) is an integral layer of understanding the prey mosaic of estuaries.

\section{CONCLUSION}

Here we integrated understanding of the spatial and temporal dynamics of zooplankton and their consumption by 4 species of fishes, but it is important to consider potential limitations of our study. We discovered that juvenile coho salmon Oncorhynchus kisutch primarily consumed terrestrial insects and fish; however, because these prey items are not adequately sampled by vertical plankton tows with the mesh size we used (Brodeur et al. 2011), we could not assess the abundance of these important prey sources across space or time. Our inference on harpacticoid copepod abundance is also based on what we sampled in the water column, yet they are associated with meiobenthic and epiphytic habitat (Alheit \& Scheibel 1982, Steinarsdóttir et al. 2010). Juvenile salmon are more likely feeding in the water column (Clark \& Levy 1988) and less so directly from substrate or blades of eelgrass. Thus, we believe that our zooplankton sampling likely represented relative densities that these fish might be encountering but lacks the ability to properly identify epibenthic zooplankton population sources, like that of harpacticoid copepods. With the example of harpacticoid copepod abundance in the environment, it is also difficult to tease apart the effects of bottom-up biophysical processes or phenology of zooplankton and top-down effects from predation. Furthermore, diet samples only represent a snapshot of what an individual fish was eating and only from locations where fish were present at the time of sampling. Isotope and fatty acid analyses could provide additional longer-term perspectives on diet trends (Daly et al. 2010, Selleslagh et al. 2015), but we believe that our study captures variability in diets and provides a picture of primary and secondary prey types consumed in the Skeena River estuary. Last, when calculating Chesson's alpha, we assumed that diet snapshots were representative of the site where samples were taken from, but the duration required to travel between sites by fish is less than that of egestion (Brett \& Glass 1973, Brodeur \& Pearcy 1987). However, we compared Chesson's alpha results from spatially averaged zooplankton abundances and found only minor differences. Thus, our study has important limitations but also contributes to the relatively understudied fields of the prey basis of nursery function in estuaries (Sheaves et al. 2015).

Collectively, our study highlights how 4 culturally, economically, and ecologically important fish species integrate with prey differently across the dynamic seascape of a major estuary. We found that few biophysical factors covaried with herring Clupea pallasii and smelt Hypomesus pretiosus diets other than total CPUE, suggesting that their diets may be influenced most by the number of fish present and less so by abiotic conditions. In contrast, multiple abiotic variables 
covaried with the abundance of certain prey in juvenile coho salmon diets, suggesting that there might be stronger impacts on their foraging success with abiotic changes. In addition to integrating with prey across the biophysical dynamics of the seascape, populations of juvenile salmon enter the Skeena River estuary at a diversity of times and may interact with different peaks of zooplankton abundance in different seascape conditions (Carr Harris et al. 2018). Thus, different populations' diets may be affected differently depending on when they enter the estuary.

The spatial and temporal asynchronies in different prey abundances and the ubiquity and abundance of others within the Skeena River estuary may provide extended and buffered foraging opportunities for cooccurring mobile consumers. Juvenile salmon diets may benefit from a diverse prey portfolio that buffers them from fluctuations in a single prey item or allows them to capitalize on easily captured prey (Armstrong et al. 2016). Harpacticoid copepods are one example of a non-evasive prey and could occur in adequate abundances in patches, such as over eelgrass habitats (Kennedy et al. 2018), to support salmon. Pacific herring and surf smelt appear more adapted to forage on the most abundant prey group (Hill et al. 2015), the highly evasive but ubiquitous calanoid copepods in this system. However, calanoid copepod abundance is correlated with salinity, and calanoid copepod distribution may change if river flow changes the salinity gradient with climate change or anthropogenic development (Sherwood et al. 1990, Nohara et al. 2006). Our work adds to the growing appreciation that estuary seascapes have dynamic and complex prey mosaics that underpin their function as nursery and foraging habitats (Nagelkerken et al. 2015, Sheaves et al. 2015) and may be affected through multiple biophysical processes.

Acknowledgements. This research is part of a collaboration between Lax Kw'alaams First Nation, Skeena Fisheries Commission, and Simon Fraser University. Any opinions, findings, conclusions, or recommendations expressed in this paper are those of the authors and do not necessarily reflect the views of the partner organizations. We sincerely thank Bill Shepert, Jen Gordon, John Latimer, Harvey James Russell, Wade Helin, Jim Henry Jr., Devin Helin, Katelyn Cooper, and Brandon Ryan from Lax Kw'alaams Fisheries Department along with David Doolan from Metlakatla Fisheries Program for providing field and logistical support. We also thank Biologica Environmental Services Ltd. for their thorough identification, enumeration, and weighing of the diet samples. We are grateful to many members of the Earth to Oceans Research Group and Salmon Watersheds Lab for advice and inspiration. This research was supported by Liber Ero Foundation, Natural Sciences and Engineering Research Council, and the Coast Opportunities Fund.

\section{LITERATURE CITED}

Ajmani AM (2011) The growth and diet composition of sockeye salmon smolts in Rivers Inlet, British Columbia. University of British Columbia, Vancouver

Alheit J, Scheibel W (1982) Benthic harpacticoids as a food source for fish. Mar Biol 70:141-147

Arditi R, Ginzburg LR (1989) Coupling in predator-prey dynamics: ratio-dependence. J Theor Biol 139:311-326

Armstrong JB, Takimoto G, Schindler DE, Hayes MM, Kauffman MJ (2016) Resource waves: phenological diversity enhances foraging opportunities for mobile consumers. Ecology 97:1099-1112

Babyak MA (2004) What you see may not be what you get: a brief, nontechnical introduction to overfitting in regression-type models. Psychosom Med 66:411-421

Barry JP, Dayton PK (1991) Physical heterogeneity and the organization of marine communities. In: Kolasa J, Pickett STA (eds) Ecological heterogeneity. Springer, New York, NY, p 270-320

Beck MW, Heck KL, Able KW, Childers DL and others (2001) The identification, conservation, and management of estuarine and marine nurseries for fish and invertebrates. Bioscience 51:633-641

* Berg L, Northcote TG (1985) Changes in territorial, gill-flaring, and feeding behavior in juvenile coho salmon (Oncorhynchus kisutch) following short-term pulses of suspended sediment. Can J Fish Aquat Sci 42:1410-1417

Birtwell IK, Nassichuk MD, Beune H (1987) Underyearling sockeye salmon (Oncorhynchus nerka) in the estuary of the Fraser River. In: Smith HDL, Margolis L, Wood CC (eds) Sockeye salmon (Onchorhynchus nerka) in the estuary of the Fraser River. Fisheries and Oceans Canada, Ottawa, p 25-35

Bollens SM, Hooff RV, Butler M, Cordell JR, Frost BW (2010) Feeding ecology of juvenile pacific salmon (Oncorhynchus spp.) in a northeast Pacific fjord: diet, availability of zooplankton, selectivity for prey, and potential competition for prey resources. Fish Bull 108:393-407

Bonferroni C (1936) Teoria statistica delle classi e calcolo delle probabilita. Pubbl R Ist Super Sci Econ Commericiali Fir 8:3-62

* Boström C, Pittman SJ, Simenstad C, Kneib RT (2011) Seascape ecology of coastal biogenic habitats: advances, gaps, and challenges. Mar Ecol Prog Ser 427:191-217

* Bottom DL, Jones KK (1990) Species composition, distribution, and invertebrate prey of fish assemblages in the Columbia River estuary. Prog Oceanogr 25:243-270

Brett JR, Glass NR (1973) Metabolic rates and critical swimming speeds of sockeye salmon (Oncorhynchus nerka) in relation to size and temperature. J Fish Res Board Can 30:379-387

* Brodeur RD (1991) Ontogenetic variations in the type and size of prey consumed by juvenile coho, Oncorhynchus kisutch, and Chinook, O. tshawytscha, salmon. Environ Biol Fishes 30:303-315

* Brodeur RD, Pearcy WG (1987) Diel feeding chronology, gastric evacuation and estimated daily ration of juvenile coho salmon, Oncorhynchus kisutch (Walbaum), in the coastal marine environment. J Fish Biol 31:465-477 
Brodeur RD, Daly EA, Schabetsberger RA, Mier KL (2007a) Interannual and interdecadal variability in juvenile coho salmon (Oncorhynchus kisutch) diets in relation to environmental changes in the northern California Current. Fish Oceanogr 16:395-408

Brodeur RD, Daly EA, Sturdevant MV, Miller TW and others (2007b) Regional comparisons of juvenile salmon feeding in coastal marine waters off the west coast of North America. Am Fish Soc Symp 57:183-203

Brodeur RD, Daly EA, Benkwitt CE, Morgan CA, Emmett RL (2011) Catching the prey: sampling juvenile fish and invertebrate prey fields of juvenile coho and Chinook salmon during their early marine residence. Fish Res 108:65-73

Brooks ME, Kristensen K, van Benthem KJ, Magnusson A and others (2017) glmmTMB balances speed and flexibility among packages for zero-inflated generalized linear mixed modeling. The R Journal 9:378-400

Brown C, Laland KN (2003) Social learning in fishes: a review. Fish Fish 4:280-288

Burnham KP, Anderson DR (2002) Model selection and multi-model inference: a practical information-theoretic approach, 2nd edn. Springer, New York, NY

Buskey EJ, Lenz PH, Hartline DK (2002) Escape behavior of planktonic copepods in response to hydrodynamic disturbances: high speed video analysis. Mar Ecol Prog Ser 235:135-146

Cabin RJ, Mitchell RJ (2000) To Bonferroni or not to Bonferroni: When and how are the questions. Bull Ecol Soc Am 81:246-248

Carr-Harris C, Gottesfeld AS, Moore JW (2015) Juvenile salmon usage of the Skeena River estuary. PLOS ONE 10:e0118988

Carr Harris CN, Moore JW, Gottesfeld AS, Gordon JA and others (2018) Phenological diversity of salmon smolt migration timing within a large watershed. Trans Am Fish Soc 147:775-790

Canadian Environmental Assessment Agency (CEAA) (2016) Decision Statement Issued under Section 54 of the Canadian Environmental Assessment Act, 2012. Canadian Environmental Assessment Agency, Ottawa

* Chacin DH, Stallings CD (2016) Disentangling fine- and broad-scale effects of habitat on predator-prey interactions. J Exp Mar Biol Ecol 483:10-19

Chandler GT, Fleeger JW (1987) Facilitative and inhibitory interactions among estuarine meiobenthic Harpacticoid copepods. Ecology 68:1906-1919

Chesson J (1978) Measuring preference in selective predation. Ecology 59:211-215

* Clark CW, Levy DA (1988) Diel vertical migrations by juvenile sockeye salmon and the antipredation window. Am Nat 131:271-290

Cloern JE (1996) Phytoplankton bloom dynamics in coastal ecosystems: a review with some general lessons from sustained investigation of San Francisco Bay, California. Rev Geophys 34:127-168

Cloern JE, Foster SQ, Kleckner AE (2014) Phytoplankton primary production in the world's estuarine-coastal ecosystems. Biogeosciences 11:2477-2501

Croll DA, Marinovic B, Benson S, Chavez FP, Black N, Ternullo R, Tershy BR (2005) From wind to whales: tropic links in a coastal upwelling system. Mar Ecol Prog Ser 289:117-130

Cushing DH (1990) Plankton production and year-class strength in fish populations: an update of the match/mis- match hypothesis. In: Blaxter JHS, Southward AJ (eds) Advances in marine biology, Vol 26. Elsevier, New York, NY, p 249-293

* Daly E, Brodeur RD, Weitkamp L (2009) Ontogenetic shifts in diets of juvenile and subadult coho and chinook salmon in coastal marine waters: important for marine survival? Trans Am Fish Soc 138:1420-1438

Daly E, Benkwitt CE, Brodeur RD, Litz MN, Copeman L (2010) Fatty acid profiles of juvenile salmon indicate prey selection strategies in coastal marine waters. Mar Biol 157:1975-1987

* David V, Selleslagh J, Nowaczyk A, Dubois S and others (2016) Estuarine habitats structure zooplankton communities: implications for the pelagic trophic pathways. Estuar Coast Shelf Sci 179:99-111

* Duffy EJ, Beauchamp DA, Sweeting RM, Beamish RJ, Brennan JS (2010) Ontogenetic diet shifts of juvenile Chinook salmon in nearshore and offshore habitats of Puget Sound. Trans Am Fish Soc 139:803-823

Dunn OJ (1961) Multiple comparisons among means. J Am Stat Assoc 56:52-64

* Eggers DM (1977) The nature of prey selection by planktivorous fish. Ecology 58:46-59

Eggers DM (1982) Planktivore preference by prey size. Ecology 63:381-390

Emlen JM (1966) The role of time and energy in food preference. Am Nat 100:611-617

F Fujiwara M, Highsmith RC (1997) Harpacticoid copepods: potential link between inbound adult salmon and outbound juvenile salmon. Mar Ecol Prog Ser 158:205-216

Gibson RN, Ezzi IA (1985) Effect of particle concentration on filter- and particulate-feeding in the herring Clupea harengus. Mar Biol 88:109-116

Giske J, Aksnes DL, Fiksen Ø (1994) Visual predators, environmental variables and zooplankton mortality risk. Vie Milieu 44:1-9

* Godin JGJ (1981) Daily patterns of feeding behaviour, daily rations, and diets of juvenile pink salmon (Oncorhynchus gorbuscha) in two marine bays of British Columbia. Can J Fish Aquat Sci 38:10-15

*Gregory RS, Northcote TG (1993) Surface, planktonic, and benthic foraging by juvenile chinook salmon (Oncorhynchus tshawytscha) in turbid laboratory conditions. Can J Fish Aquat Sci 50:233-240

*Griffiths D (1973) The food of animals in an acid morland pond. J Anim Ecol 42:285-293

Griffiths D (1975) Prey availability and the food of predators. Ecology 56:1209-1214

Healey MC (1979) Detritus and juvenile salmon production in the Nanaimo estuary: I. Production and feeding rates of juvenile chum salmon (Oncorhynchus keta). J Fish Res Board Can 36:488-496

Healey MC (1980) Utilization of the Nanaimo river estuary by juvenile Chinook salmon, Oncorhynchus tshawutscha. Fish Bull 77:653-668

*Healey MC (1991) Diets and feeding rates of juvenile pink, chum, and sockeye salmon in Hecate Strait, British Columbia. Trans Am Fish Soc 120:303-318

Hill A, Daly E, Brodeur R, Hill A, Daly E, Brodeur R (2015) Diet variability of forage fishes in the Northern California Current System. J Mar Sci 146:121-130

Hitchcock C, Sober E (2004) Prediction versus accommodation and the risk of overfitting. Br J Philos Sci 55:1-34

*Hosack GR, Dumbauld BR, Ruesink JL, Armstrong DA (2006) Habitat associations of estuarine species: compar- 
isons of intertidal mudflat, seagrass (Zostera marina), and oyster (Crassostrea gigas) habitats. Estuaries Coasts 29:1150-1160

Jennions MD (2003) A survey of the statistical power of research in behavioral ecology and animal behavior. Behav Ecol 14:438-445

Kennedy LA, Juanes F, El-Sabaawi R (2018) Eelgrass as valuable nearshore foraging habitat for juvenile Pacific salmon in the early marine period. Mar Coast Fish 10: 190-203

Labropoulou M, Eleftheriou A (1997) The foraging ecology of two pairs of congeneric demersal fish species: importance of morphological characteristics in prey selection. J Fish Biol 50:324-340

Landigham JH, Sturdevant MV, Brodeur RD (1998) Feeding habits of juvenile Pacific salmon in marine waters of southeastern Alaska and northern British Columbia. Fish Bull 96:285-302

Lannin R, Hovel K (2011) Variable prey density modifies the effects of seagrass habitat structure on predator-prey interactions. Mar Ecol Prog Ser 442:59-70

Lazzaro X (1987) A review of planktivorous fishes: their evolution, feeding behaviours, selectivities, and impacts. Hydrobiologia 146:97-167

Leising AW, Yen J (1997) Spacing mechanisms within lightinduced copepod swarms. Mar Ecol Prog Ser 155: 127-135

Letcher BH, Rice JA (1997) Prey patchiness and larval fish growth and survival: inferences from an individualbased model. Ecol Model 95:29-43

Levings CD (2016) Ecology of salmonids in estuaries around the world: adaptations, habitats, and conservation. UBC Press, Vancouver

Ljungberg P, Hasper TB, Nilsson PA, Persson A (2013) Effects of small-scale habitat fragmentation on predator-prey interactions in a temperate sea grass system. Mar Biol 160:667-675

López Abbate MC, Molinero JC, Guinder VA, Dutto MS and others (2015) Microplankton dynamics under heavy anthropogenic pressure. The case of the Bahía Blanca Estuary, southwestern Atlantic Ocean. Mar Pollut Bull 95:305-314

Macdonald JS, Birtwell IK, Kruzynski GM (1987) Food and habitat utilization of juvenile salmonids in the Campbell River estuary. Can J Fish Aquat Sci 44:1233-1246

Mackas DL, Greve W, Edwards M, Chiba S and others (2012) Changing zooplankton seasonality in a changing ocean: comparing time series of zooplankton phenology. Prog Oceanogr 97-100:31-62

* Manzer J (1969) Stomach contents of juvenile Pacific salmon in Chatham Sound and adjacent waters. J Fish Res Board Can 26:2219-2223

Mauchline J (1998) The biology of calanoid copepods. Academic Press, New York, NY

* McDevitt-Irwin JM, Iacarella JC, Baum JK (2016) Reassessing the nursery role of seagrass habitats from temperate to tropical regions: a meta-analysis. Mar Ecol Prog Ser 557:133-143

Miller TW, Brodeur RD (2007) Diets of and trophic relationships among dominant marine nekton within the northern California Current ecosystem. Fish Bull 105:548-559

Moore JW, Gordon J, Carr-Harris C, Gottesfeld AS, Wilson SM, Russell JH (2016) Assessing estuaries as stopover habitats for juvenile Pacific salmon. Mar Ecol Prog Ser 559:201-215
Moore JW, Carr-Harris C, Gottesfeld AS, MacIntyre D and others (2015) Selling First Nations down the river. Science 349:596

Morgan CA, Cordell JR, Simenstad CA (1997) Sink or swim? Copepod population maintenance in the Columbia River estuarine turbidity-maxima region. Mar Biol 129: 309-317

Nagelkerken I, Sheaves M, Baker R, Connolly RM (2015) The seascape nursery: a novel spatial approach to identify and manage nurseries for coastal marine fauna. Fish Fish 16:362-371

Nakagawa S (2004) A farewell to Bonferroni: the problems of low statistical power and publication bias. Behav Ecol 15:1044-1045

Nohara D, Kitoh A, Hosaka M, Oki T (2006) Impact of climate change on river discharge projected by multimodel ensemble. J Hydrometeorol 7:1076-1089

Northcote T, Gregory R, Magnhagen C (2007) Contrasting space and food use among three species of juvenile Pacific salmon (Oncorhynchus) cohabiting tidal marsh channels of a large estuary. Can Tech Rep Fish Aquat Sci 2759, Fisheries and Oceans Canada, St John's

Ocean Ecology (2014) Skeena River estuary juvenile salmon habitat. Report prepared by Ocean Ecology for Skeena Wild Conservation Trust and Skeena Watershed Conservation Coalition. Prince Rupert

* Osgood G (2016) Historical diets of forage fish and juvenile Pacific salmon in the Strait of Georgia, 1966-1968. Mar Coast Fish 8:580-594

Palmer MA (1988) Dispersal of marine meiofauna: a review and conceptual model explaining passive transport and active emergence with implications for recruitment. Mar Ecol Prog Ser 48:81-91

* Perillo GME (1995) Definitions and geomorphologic classifications of estuaries. Dev Sedimentol 53:17-47

Pickard D, Porter M, Olson E, Connors B, Kellock K, Jones E, Connors K (2015) Skeena River estuary assessment: technical report. Pacific Salmon Foundation, Vancouver

* Pitchford WJ (2001) Prey patchiness, predator survival and fish recruitment. Bull Math Biol 63:527-546

* Price M, Glickman B, Reynolds J (2013) Prey selectivity of Fraser River sockeye salmon during early marine migration in British Columbia. Trans Am Fish Soc 142: 1126-1133

R Core Team (2017) R: a language and environment for statistical computing. R Foundation for Statistical Computing, Vienna

Rudstam LG, Aneer G, Hildén M (1994) Top-down control in the pelagic Baltic ecosystem. Dana 10:105-129

* Schoener TW (1970) Non-synchronous spatial overlap of lizards in patchy habitats. Ecology 51:408-418

* Selleslagh J, Lesourd S, Amara R (2012) Comparison of macrobenthic assemblages of three fish estuarine nurseries and their importance as foraging grounds. J Mar Biol Assoc UK 92:85-97

Selleslagh J, Blanchet H, Bachelet G, Lobry J (2015) Feeding habitats, connectivity and origin of organic matter supporting fish populations in an estuary with a reduced intertidal area assessed by stable isotope analysis. Estuaries Coasts 38:1431-1447

Sharpe C (2017) Abiotic and biotic dimensions of habitat for juvenile salmon and other fishes in the Skeena River estuary. MS thesis, Simon Fraser University, Burnaby

* Sheaves M, Baker R, Nagelkerken I, Connolly RM (2015) True value of estuarine and coastal nurseries for fish: in- 
corporating complexity and dynamics. Estuaries Coasts 38:401-414

Sherwood CR, Jay DA, Bradford Harvey R, Hamilton P, Simenstad CA (1990) Historical changes in the Columbia River Estuary. Prog Oceanogr 25:299-352

Sibert J (1979) Detritus and juvenile salmon production in the Nanaimo Estuary: II. Meiofauna available as food to juvenile chum salmon (Oncorhynchus keta). J Fish Res Board Can 36:497-503

Sih A, Englund G, Wooster D (1998) Emergent impacts of multiple predators on prey. Trends Ecol Evol 13:350-355

Simenstad CA, Fresh KL, Salo EO (1982) The role of Puget Sound and Washington coastal estuaries in the life history of Pacific salmon: an unappreciated function. In: Kennedy VS (ed) Estuarine comparisons. Elsevier, New York, NY, p 343-364

Sims DW, Southall EJ, Humphries NE, Hays GC and others (2008) Scaling laws of marine predator search behaviour. Nature 451:1098-1102

Editorial responsibility: Antonio Bode, A Coruña, Spain
Steinarsdóttir MB, Ingólfsson A, Ólafsson E (2010) Field evidence of differential food utilization of phytal harpacticoids collected from Fucus serratus indicated by $\delta^{13} \mathrm{C}$ and $\delta^{15} \mathrm{~N}$ stable isotopes. Estuar Coast Shelf Sci 88:160-164

Telesh IV, Khlebovich VV (2010) Principal processes within the estuarine salinity gradient: a review. Mar Pollut Bull 61:149-155

* Trites RW (1956) The oceanography of Chatham Sound, British Columbia. J Fish Res Board Can 13:385-434

Tschaplinski PJ (1987) The use of estuaries as rearing habitats by juvenile coho salmon. Fisheries and Oceans Canada, Research Branch, Pacific Biological Station, Nanaimo

*Werner EE, Gilliam JF (1984) The ontogenetic niche and species interactions in size-structured populations. Annu Rev Ecol Syst 15:393-425

Yang LH, Bastow JL, Spence KO, Wright AN (2008) What can we learn from resource pulses? Ecology 89:621-634

Submitted: September 27, 2018; Accepted: February 14, 2019 Proofs received from author(s): March 12, 2019 